\title{
A replacement of chromate coating for adhesive bonding of stainless steel in a corrosive environment
}

\author{
Khaled Alawadhi $^{1 *}$, Richard Brown ${ }^{2}$, Jalal Alsarraf ${ }^{1}$ \\ ${ }^{I}$ Department of Automotive and Marine Technology, The Public Authority for Applied Education and Training, \\ Shuwaikh, Kuwait City 70654, Kuwait \\ ${ }^{2}$ Department of Chemical Engineering, The University of Rhode Island, Kingston RI 02881, USA \\ *Corresponding author E-mail: ka.alawadhi@paaet.edu.kw
}

Copyright $(\mathcal{C} 2014$ Khaled Alawadhi et al. This is an open access article distributed under the Creative Commons Attribution License, which permits unrestricted use, distribution, and reproduction in any medium, provided the original work is properly cited.

\begin{abstract}
For adhesive bonding of stainless steel to itself, a surface treatment involving chromates is used. However, chromates are environmentally unfriendly so a replacement is being sought. In this paper, an alternative to chromate was investigated. The standard test method, ASTM D 1002, was used to measure the failure load of adhesively bonded stainless steel samples. A general-purpose epoxy adhesive was used.

To simulate marine exposure, adhesively bonded samples were placed in a 5\% salt spray for extended periods of time, up to five weeks. Results indicated that the initial shear strength of adhesive joints prepared with a traditional chromate preparation was $25 \%$ greater than the new, alternative coating. However, more importantly, the rate of decrease in strength with salt spray exposure was greater for the chromate than for the alternative. After 21 days, both bonding surface treatments had the same strength. However, after this period of time, the alternative was stronger than the chromate treatment, indicating that the alternative was a more durable coating.

An adhesive/adherent coated system was investigated using a finite element method in order to investigate the influence of adhesive thickness between the adhesive and the adherent, and the residual stress in the adhesive layer.
\end{abstract}

Keywords: Adhesive, Alternative Coating, Crevice Corrosion, Potentio-Dynamic, Salt Spray.

\section{Introduction}

Chromate conversion coatings have been applied successfully on stainless steel SS 316L for a long time to improve the corrosion resistance and adhesion to both itself and other coatings and adhesives. However, the need for more environmentally friendly processes in the marine industry has led to the development of various chromate-free alternatives. Often, these traditional conversion coatings contain hexavalent chromium. Although, hexavalent chromium compounds (chromates) offer outstanding corrosion protection, they are known carcinogens and an Environmental Protection Agency (EPA) priority pollutant [1]. Due to changing environmental regulations, a significant push exists to find new, alternative conversion coatings, i.e. products that do not contain chromium. Stainless steel $316 \mathrm{~L}$ is very attractive for many industrial applications, such as oil and gas production, and in the petrochemical and pharmaceutical industries, due to its relatively high corrosion resistance, good fabricability and weldability [2], [3].

Coatings with very low electronic conductance, such as $\mathrm{SiO}_{2}$, non-conducting $\mathrm{Al}_{2} \mathrm{O}_{3}$, and mixed-oxide coatings (TiO $\mathrm{SiO}_{2}$, and $\left.\mathrm{Al}_{2} \mathrm{O}_{3}\right)$; have been reported to protect metals efficiently against corrosion [4]. Titanium dioxide $\left(\mathrm{TiO}_{2)}\right.$ has gained extensive interest during recent years because of its good corrosion resistance as well as playing an important role in various applications, such as the photo-catalysis process for water and air depollution. However, these coatings present a low adhesion to the metal substrate at high temperatures [5].

The formation of a conversion layer prior to coating deposition may represent a solution to this problem. For example, conversion layers obtained by chemical treatment may have a high surface area and an interesting morphology with micropores and cavities in a large size range [6]. Such a microstructure helps to anchor further deposits [7], and various layers can be deposited by different methods on top of the conversion coating [8]. Moreover, subsequent thermal 
treatment may induce a reaction between compounds of the conversion layer and the deposit and further enhance adhesion [9].

Adhesive bonding is a widely used joining process in the worldwide production of engineering products. It forms an essential part of the laminating process in multi-material sandwich structures, and it is also used for structural connections between multi-material components as well as for bonding of automotive and aeroplane parts [10].

The geometrical configuration of bonded parts is essential to obtain enough structural strength. Even joints that have the same adhesively bonded area may have different joint strength according to the bonded configuration [11]. The adhering conditions are also important to attain the joint strength, such as surface roughness of the adhering surface, the thickness of the adhesive layer, the pressure applied to the adhesive resin and its holding time, and the curing conditions of adhesive resin; all these are substantial factors affecting the joint strength [12].

The aim of this paper is to replace a traditional chromate coating, applied as part of the adhesive bonding of stainless steel SS 316 to itself, with a more environmentally friendly coating.

\section{Materials and experimental method}

\subsection{Materials and specimen preparation}

Rectangular specimen samples used in all tests were cut from 316L stainless steel, $1.6 \mathrm{~mm}$ thick, $75 \mathrm{~mm}$ long and 25 $\mathrm{mm}$ wide. The chemical composition of the steel is given in Table 1. In order to prepare the samples for corrosion tests and substrates for adhesive bonding to each other, the specimens were ground up to 1000-grit SiC paper, degreased with acetone, dried with hot pressurized air, and kept in a desiccator until use.

Adhesive (epoxy) was applied to the area across the end of both metal sheets so that the adhesive would cover a space approximately $25 \mathrm{~mm}$ by $25 \mathrm{~mm}$. The thickness of the adhesive layer was settled to $0.25-0.125 \mathrm{~mm}$ by using an appropriate fixture device and then allowed to cure for 24 hours at room temperature.

Table 1: Chemical Composition of 316L Stainless Steel

\begin{tabular}{cccccccc}
\multicolumn{7}{c}{ Table 1: Chemical Composition of 316L Stainless Steel } \\
\hline Element & $\mathrm{C}$ & $\mathrm{Cr}$ & $\mathrm{Ni}$ & $\mathrm{Mg}$ & $\mathrm{Si}$ \\
\hline$(\mathrm{Wt} \%)$ & 0.2 & $16-18$ & $10-14$ & 2.00 & 1.00 & 0.03 & \\
\hline
\end{tabular}

\subsection{Coating of 316L by chromium dioxide or titanium dioxide}

To etch the stainless steel (316L), it was immersed for approximately three quarter of its length in bath 1 ( 25 grams of sodium metasilicate, 11 grams of tetrasodium pyrophosphate, 11 grams of sodium hydroxide, 3 grams of nacconol dissolved in $950 \mathrm{cc}$ of DI) for 10 minutes at a desired temperature of $60-70^{\circ} \mathrm{C}$ maintained with a circulating system operation, then rinsed with deionized water (DI) and finally immersed in bath 2 (100 grams of chromium trioxide) for another 10 minutes at the same temperature as in the previous case.

The substrate was washed in cold running DI and dried in a forced-draft oven at less than $60^{\circ} \mathrm{C}$, then cooled to room temperature. After cooling, adhesive was applied to some of the specimens using the standard method. Some of the cooled specimens were tested electrochemically without adhesive present but after chemical surface preparation.

The same methodology was used for coating by titanium dioxide but with different concentrations of substances supplied as follows: bath 1 (25 grams of sodium metasilicate, 11 grams of tetrasodium pyrophosphate, 11 grams of sodium hydroxide, 3 grams of nacconol dissolved in $950 \mathrm{cc}$ of DI) then immersed in bath 3 (50 grams of titanium dioxide dissolved in $500 \mathrm{cc}$ of DI).

\subsection{Electrochemical measurements}

The potentio-dynamic polarization measurements were carried out on an EG\&G M352 system consisting of a model 273A with electrometer and corrosion cell (Flat holder) by using a typical 3-electrode corrosion cell with a saturated calomel electrode as reference and platinum as counter electrode in order to study the corrosion behavior of the $\mathrm{Cr}_{2} \mathrm{O}_{3}$ and $\mathrm{TiO}_{2}$ coated stainless steel. A schematic diagram of the experimental setup is shown in Fig. 1. These data for the two different chemical surface preparations were compared with the uncoated material.

During corrosion testing, samples were exposed to nitrogen de-aerated $3.5 \% \mathrm{NaCl}$ solutions at the controlled room temperatures of $25^{\circ} \mathrm{C}$. After 5-mins exposure to the test solution, potentio-dynamic polarization measurements were carried out using an initial potential of $-125 \mathrm{mV}$ from OCP and maximum potential of $400 \mathrm{mV}$ from OCP with a scan rate of $0.1 \mathrm{mV} / \mathrm{s}$. 


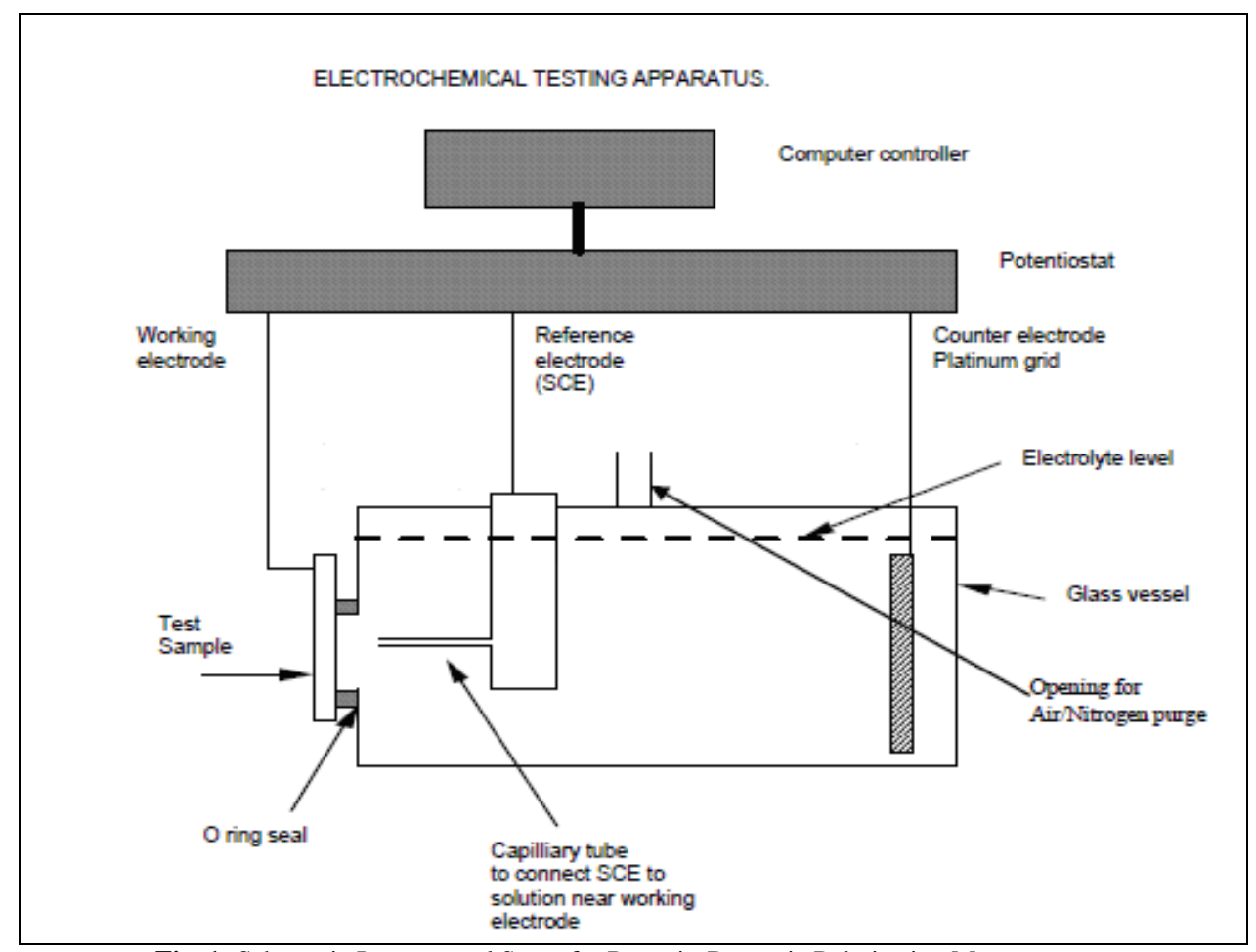

Fig. 1: Schematic Instrumental Setup for Potentio-Dynamic Polarization Measurements

\subsection{Corrosive exposure}

To investigate the effect of marine exposure, lap joint samples were placed in a salt spray apparatus for increasing exposure periods and the residual shear strength measured. The salt spray test is a standardized test method used to study the corrosion resistance of coated samples. It is an accelerated and severe test that produces a corrosive attack on the samples and allows prediction of the suitability of the coating as a protective finish.

The salt spray tests, which represent the testing of materials under severe conditions of corrosive marine environment salt, were carried out in a salt spray fog chamber, following ASTM B117. Lap shear adhesively bonded test coupons with a surface chemical treatment with either $\mathrm{Cr}_{2} \mathrm{O}_{3}$ or $\mathrm{TiO}_{2}$ were exposed continuously to salted solutions of $3.5 \%$ $\mathrm{NaCl}(\mathrm{pH}=6.5)$ for time periods varying from 1-5 weeks with a controlled temperature of $95^{\circ} \mathrm{F}\left(35^{\circ} \mathrm{C}\right)$.

\subsection{Residual strength testing}

After marine exposure for various increasing periods of time, tensile testing to measure residual bond strength was performed on adhesively bonded stainless steel samples following up to five weeks of salt spray exposure. The tests were conducted using a tensile testing machine in accordance with ASTM D 1002. The loading was applied immediately to the specimen at rates of 1200-1400 psi of the shear area per minute. The rate of the loading was approximated by a free crosshead speed of $0.05 \mathrm{inch} / \mathrm{min}$. These data were compared to adhesively bonded samples that had not received marine exposure.

\section{Results and discussion}

\subsection{Polarization curves}

In order to quantify corrosion behavior and determine its ability to passivate in a chloride environment, poteniodynamic testing was employed. Some representative potentio-dynamic polarization curves for the coated SS $316 \mathrm{~L}$ in de-aerated 3.5\% NaCl are shown in Figs. 2 and 3. The corrosion potential for bare SS 316L (Fig. 2) was around -0.06 (V vs. SEC), while coated samples with chromium and titanium dioxide were +0.04 (V vs. SCE) and - 0.039 (V vs. SEC), respectively, as shown in (Fig. 3).

The pitting potential, Epit, is assessed as that potential at which a consistent increase in current density occurs, indicating the initiation of non-passivating pits. It was clear that the Epit for the sample coated with chromium dioxide is similar to bare metal and the titanium dioxide coated sample. The chromium pits at $0.1 \mathrm{~V}$ as does the SS 316L. The difference is when going back down with the potential. The SS 316L has current density at least one order of magnitude smaller than the chromium when returning the OCP. 
The potentio-dynamic polarization behavior of the chromium coated SS 316L was similar to that attained for the uncoated SS 316L (Fig. 3). However, important exceptions were a small increase in the breakdown potential and enlargement of the hysteresis loop. This latter behavior suggests a higher propensity towards pitting attack. The coating of SS $316 \mathrm{~L}$ with titanium oxide induced a substantial change in the polarization behavior (Fig. 3). The corrosion potential and the anodic branch of the polarization scan shifted towards the active direction, with a decrease in the accompanying current. The curve of reverse scan overlapped with that of the transpassive region, indicating a lack of hysteresis. This behavior suggests that the titanium coated $316 \mathrm{~L}$ did not suffer localized corrosion in the chloride environment. In general, the potentio-dynamic data show that $\mathrm{Cr}_{2} \mathrm{O}_{3}$ treatment exhibits a tendency to localized corrosion while the $\mathrm{TiO}_{2}$ treatment does not.

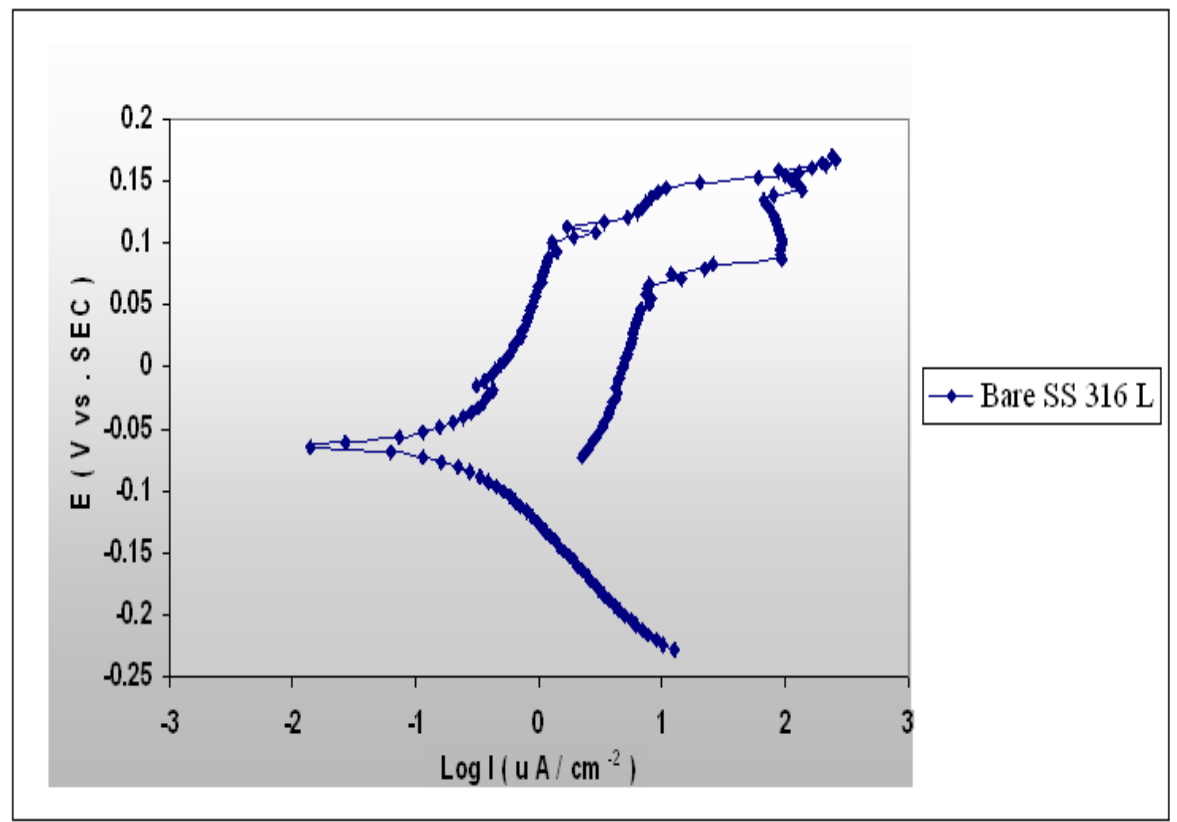

Fig. 2: Potentio-Dynamic Polarization Curve for SS 316L Non-Coated and Exposed to De-Aerated 0.1M NaCl Solution

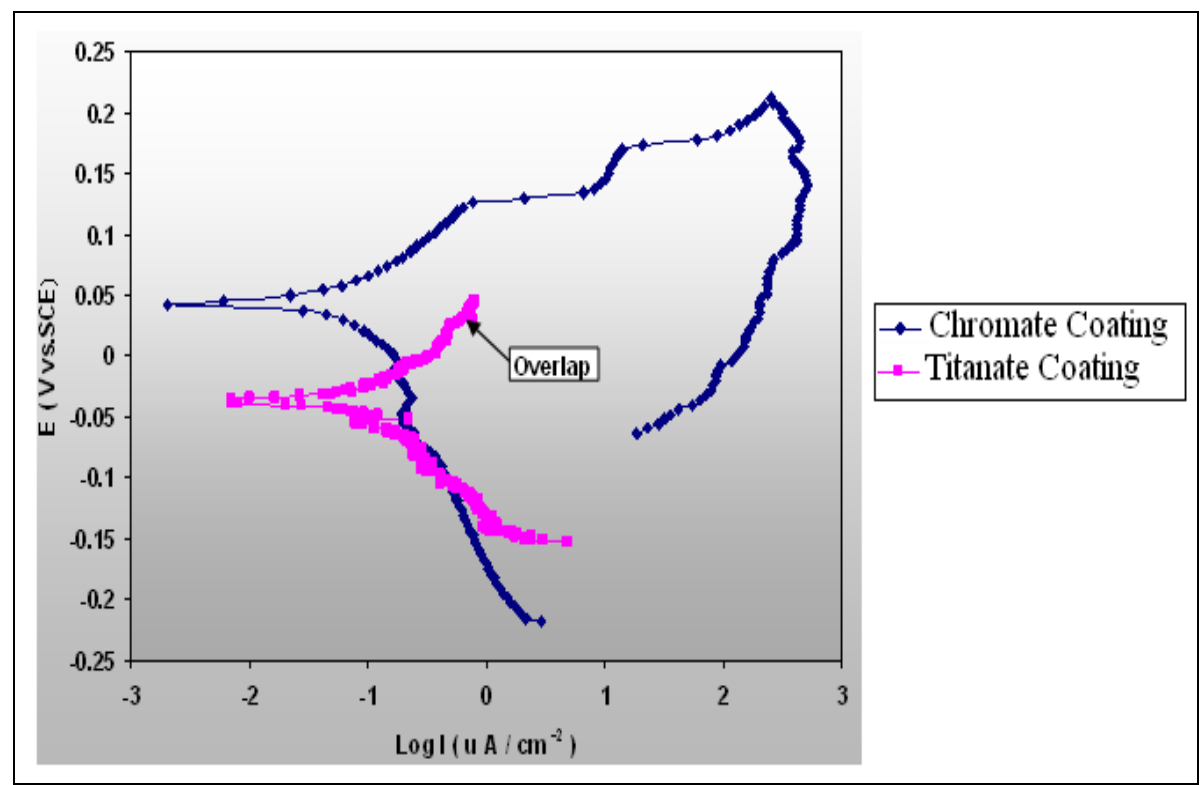

Fig. 3: Potentio-Dynamic Polarization Curve For SS 316L Coated with Chromium Dioxide and Titanium Dioxide Exposed to De-Aerated 0.1M Nacl Solution

\subsection{Residual strength}

To measure the adhesive strength of bonds using the different surface treatments, a standard test method, ASTM D 1002, was used. This measured the apparent shear strength of single lap joints made by adhesively bonding metal specimens together. A general-purpose epoxy adhesive was used in the experiments. 
The bar diagrams in Fig. 4 show the tensile test values for SS 316L exposed to atmospheric conditions over a five week period. An adhesive thickness of $0.125 \mathrm{~mm}$ was used for all samples, whether non-surface treated before adhesive bonding or chemically surface treated with either $\mathrm{Cr}_{2} \mathrm{O}_{3}$ or $\mathrm{TiO}_{2}$. It was clear that chemical treatment with $\mathrm{Cr}_{2} \mathrm{O}_{3}$ did induce an increase in failure load. When the exposure time was prolonged, i.e. up to five weeks, samples coated with $\mathrm{TiO}_{2}$ showed a higher strength than samples coated with $\mathrm{Cr}_{2} \mathrm{O}_{3}$. The residual strengths for the samples with $\mathrm{Cr}_{2} \mathrm{O}_{3}$ or $\mathrm{TiO}_{2}$ treatment under aggressive conditions using salt spray are shown in Fig. 5, for two different thicknesses of 0.125 or $0.250 \mathrm{~mm}$. Each data point in the figures represents the average failure load of no less than two specimens. The measured average failure load displayed a steady decrease over the range of five weeks of marine exposure for both thicknesses. However, for the $\mathrm{TiO}_{2}$ treated surfaces, after three weeks for the $0.250 \mathrm{~mm}$ thick coating and also after two weeks for the $0.125 \mathrm{~mm}$ thick adhesive, a slight increase in average failure load was found. After this slight increase, a gradual decrease was found, but at higher levels than for the $\mathrm{Cr}_{2} \mathrm{O}_{3}$ treated surfaces.

The results indicated that the shear strength of adhesive joints coated with $\mathrm{Cr}_{2} \mathrm{O}_{3}$ decreased in strength to a value less than the joints treated with $\mathrm{TiO}_{2}$, even though the initial strength was higher, so the durability of the $\mathrm{TiO}_{2}$ treated joints was improved over the $\mathrm{Cr}_{2} \mathrm{O}_{3}$ treated joints. In general, for the specimens coated with $\mathrm{Cr}_{2} \mathrm{O}_{3}$, their bond strength decreased by $64 \%$, while for bonded specimens coated with $\mathrm{TiO}_{2}$, they decreased by $39 \%$. Irrespective of surface treatment applied before the adhesive application, a thin adhesive thickness of $0.125 \mathrm{~mm}$ yielded higher failure loads than the thick adhesive of $0.250 \mathrm{~mm}$, as shown in Fig. 5.

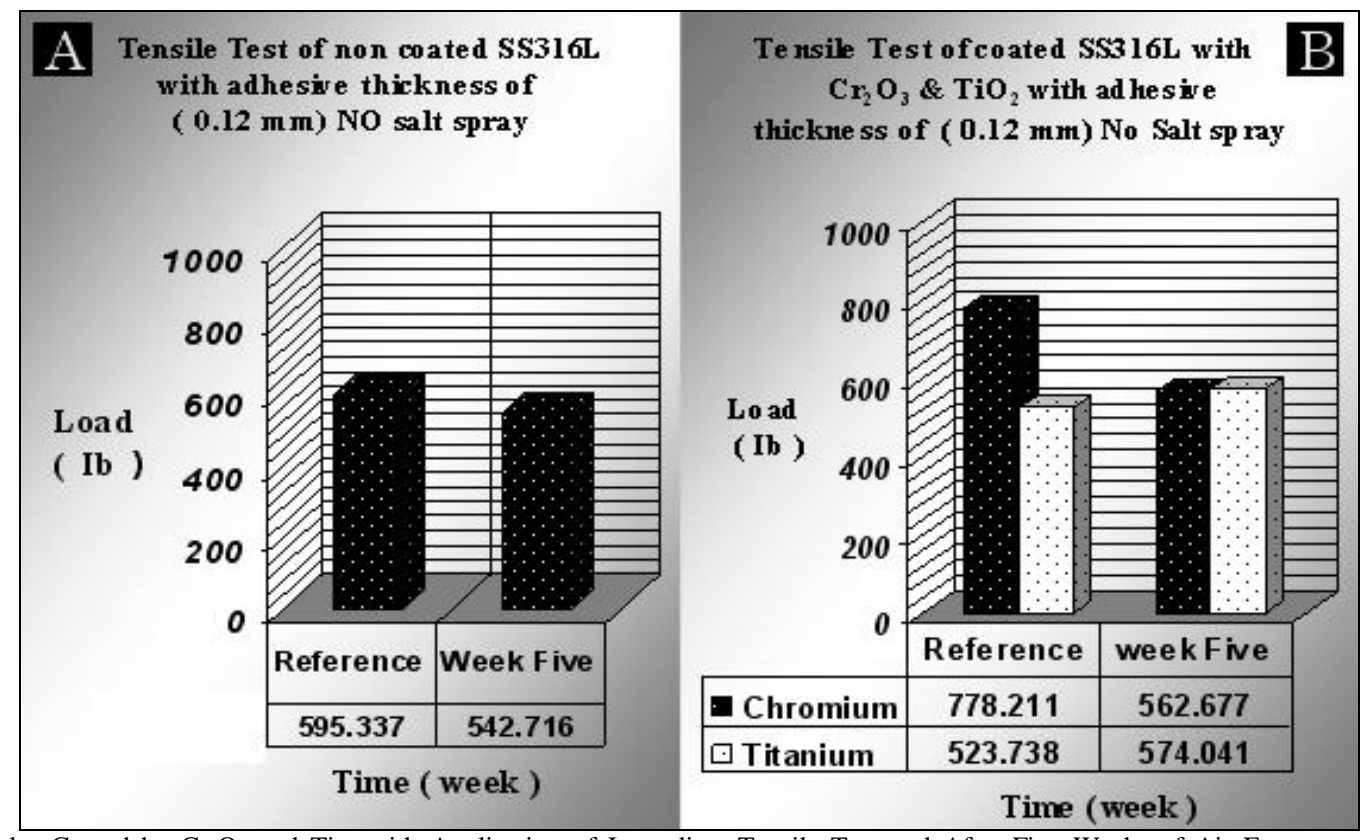

Fig. 4: Samples Coated by $\mathrm{Cr}_{2} \mathrm{O}_{3}$ and $\mathrm{Tio}_{2}$ with Application of Immediate Tensile Test and After Five Weeks of Air Exposure with Adhesive Thickness of $0.12 \mathrm{Mm}$

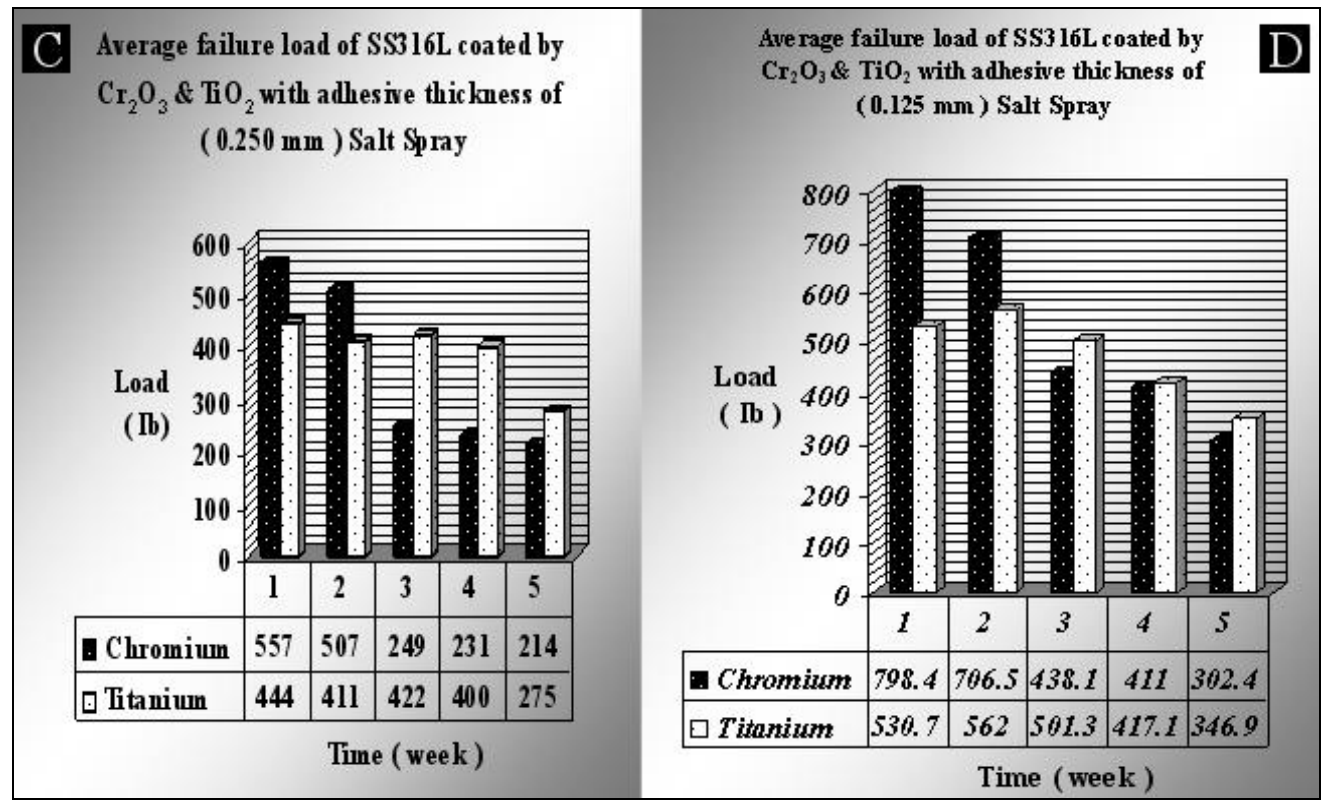


Fig. 5: Average Failure Loads for Coated Samples Either by $\mathrm{Cr}_{2} \mathrm{O}_{3}$ and $\mathrm{Tio}_{2}$ Exposed to Salt Spray Test on Weekly Bases with Adhesive Thickness of C: $0.250 \mathrm{Mm}$ and D: $0.125 \mathrm{Mm}$

\subsection{Tensile strength}

The adhesive shear strength $(\tau)$ has been calculated as a maximum shear stress achieved in an adhesive layer, based on recorded maximum tensile forces for each tested joint [13]:

$$
\tau_{a}=\frac{F_{\max }}{l \cdot a}
$$

And, a joint tensile strength $(\sigma)$ as a maximum tensile stress transferred crossover the joint [13]:

$$
\sigma_{s}=\frac{F_{\max }}{s \cdot a}
$$

In accordance with Equation (A), differences in shear strength after five weeks of exposure for the different exposure periods can clearly be seen in Fig. 6.

Depending on the amount of adhesive thickness $(0.25 \mathrm{~mm})$, the mean adhesion strength for samples coated with Cr after two weeks of exposure dropped from 3.8 to $1.4 \mathrm{MPa}$, while the samples coated with Ti dropped from 3.1 to $1.92 \mathrm{MPa}$.

For adhesive thickness of 0.125 , shear strength of specimens coated with both $\mathrm{Cr}$ and $\mathrm{Ti}$ with time shows the same trend as the shear strength results with adhesive thickness of 0.25 , but a marked constant in strength values can be observed for those specimens coated with Ti.

It was clear that the strength of the samples coated with $\mathrm{Cr}$ and $\mathrm{Ti}$ decreases as the adhesive thickness increases. Correspondingly, the average shear stress values for the coated surface also decreases.

The tensile strength as a function of five weeks of exposure is plotted in Fig. 7. The tensile results for specimens coated with $\mathrm{Cr}$ or $\mathrm{Ti}$ at two adhesive thicknesses follow a similar trend to those observed for shear results.

Tensile test results indicated that the samples coated with Ti had a high effect on the strength of the joint, typically 34 $38 \%$ reduction after five weeks of exposure for two adhesive thicknesses. While the sample coated with $\mathrm{Cr}$ resulted in a $61-62 \%$ reduction.

The results presented in Figs. 6 and 7 clearly indicate that both shear and tensile stress are affected by adhesive thickness and coated substrate parameter. These differences have reached the point that by increasing the adhesive thickness, it increases the rate of strength loss.

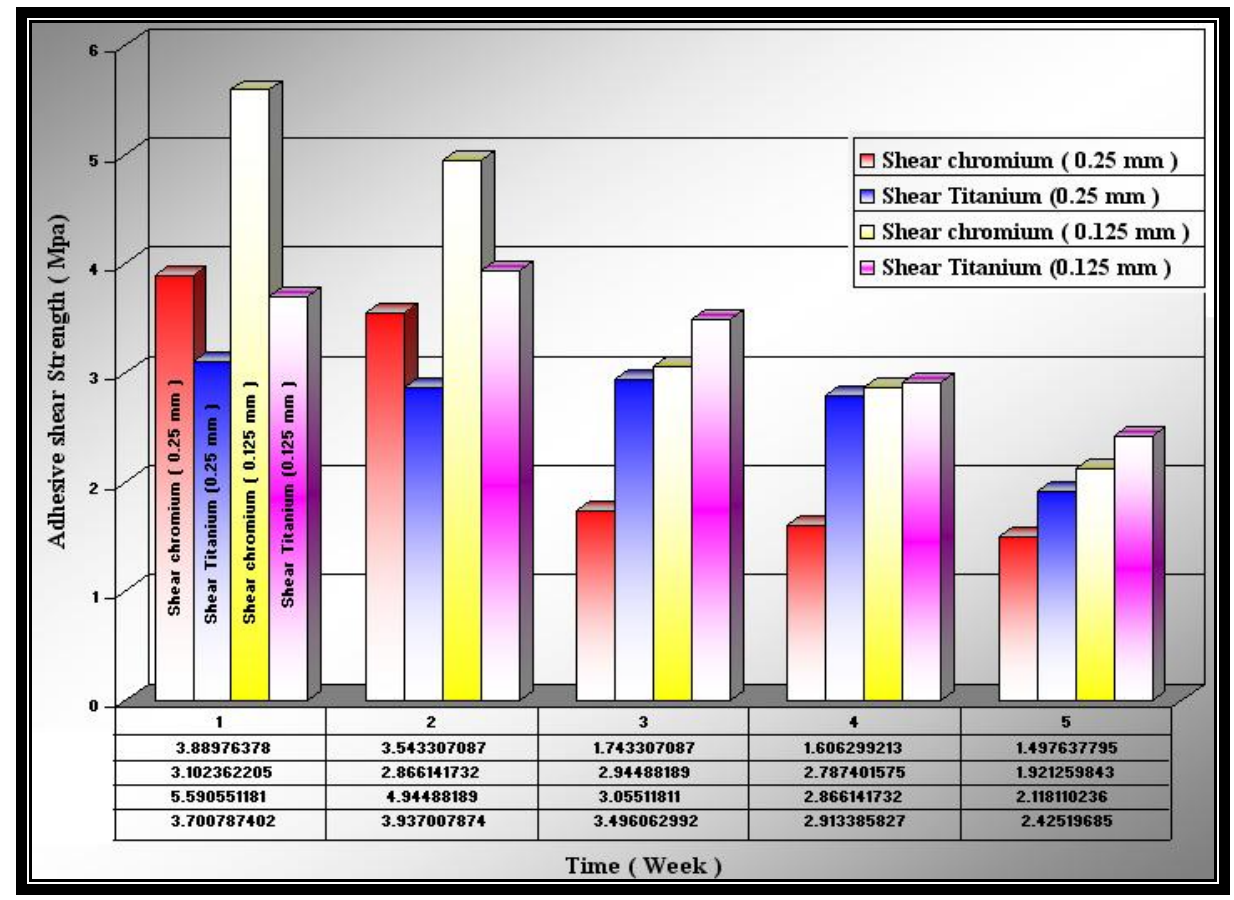

Fig. 6: Apparent Shear Strength versus Time (Week) for SS 316L at Two Adhesive Thicknesses of $0.125 \mathrm{Mm} \& 0.25 \mathrm{Mm}$ 


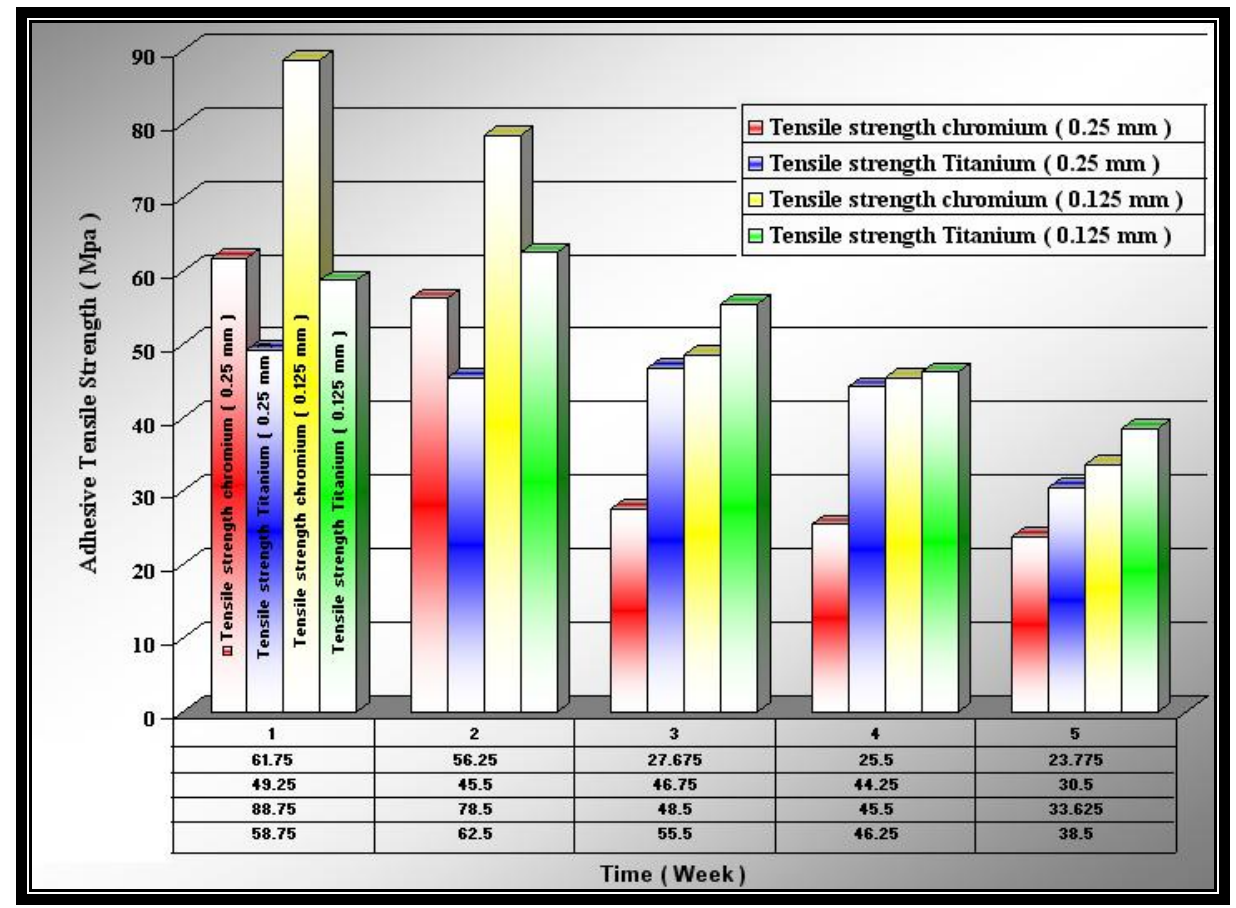

Fig. 7: Apparent Tensile Tests versus Time (Week) For SS 316L at Two Adhesive Thicknesses of $0.125 \mathrm{Mm} \& 0.25 \mathrm{Mm}$

\subsection{Finite element analysis (FEA)}

An effective steel-to-steel adhesive joint normally incorporates a single lap shear joint design, adhesive layers and cores. The lap joint (Fig. 8) is capable of transmitting structural loads and maintaining the integrity of the steel-to-steel joint. Fig. 8 represents a manufacturing approach to make a steel-to-steel joint. An adhesive can be applied to the steel with a length of $25.4 \mathrm{~mm}$, on to which the other steel part is bonded with an adhesive. After making the steel-to-steel adhesive joint, the bonded steel receiver can be constrained at either end on the test rig along a distance of approximately $25.4 \mathrm{~mm}$. Further, for the given simulation, the substrate, i.e. stainless steel, has been coated with chromium or titanium.

The FEA part has been employed for the purpose of investigating the effect of the adhesive thickness on the joint performance. Particular consideration is given to the formulation of the finite element model and its validation against experimental results for adhesively coated bonded samples with both adhesive thicknesses of $0.125 \mathrm{~mm}$ and $0.25 \mathrm{~mm}$ exposed to salt spray for the first week.

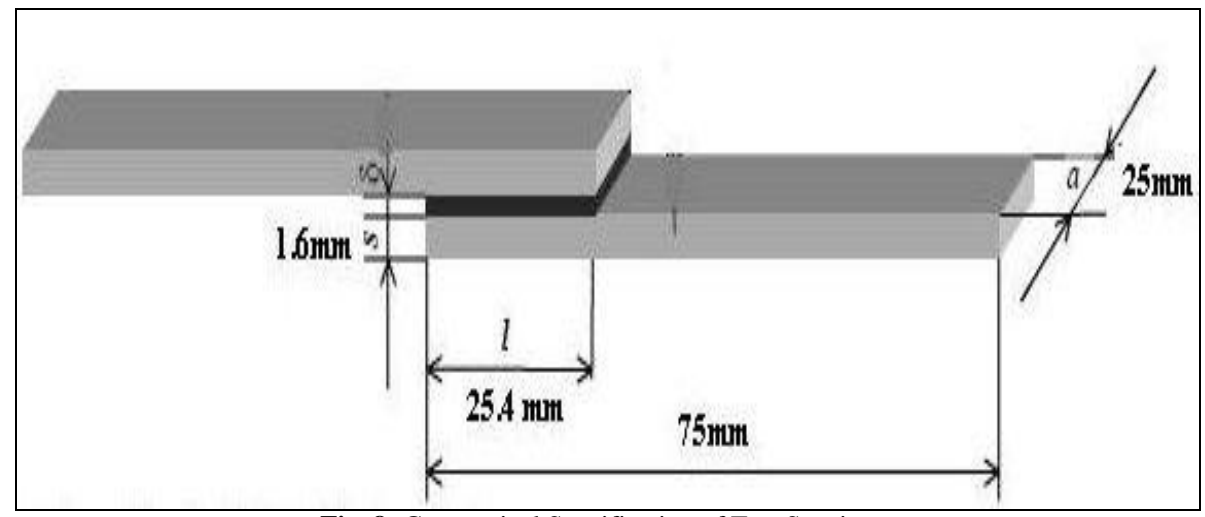

Fig. 8: Geometrical Specification of Test Specimen

\section{Modeling method}

The modeling method was developed based on commercial finite element software, Nx-NASTRAN. A threedimensional (3-D) model was used in which the metal and adhesive were meshed with solid brick elements. The number of layers and material property orientations in the steel and adhesive can be considered using this modeling method. Fig. 9 shows the modeling approach used in the FEA of steel-to-steel adhesive joint, which includes modeling input and load application. The coating layer has also been considered in the model, as described in Fig. 9. The model 
input includes the joint geometry and materials properties. Material properties were obtained from public literature. The model was used to predict the strength of steel-to-steel structures.

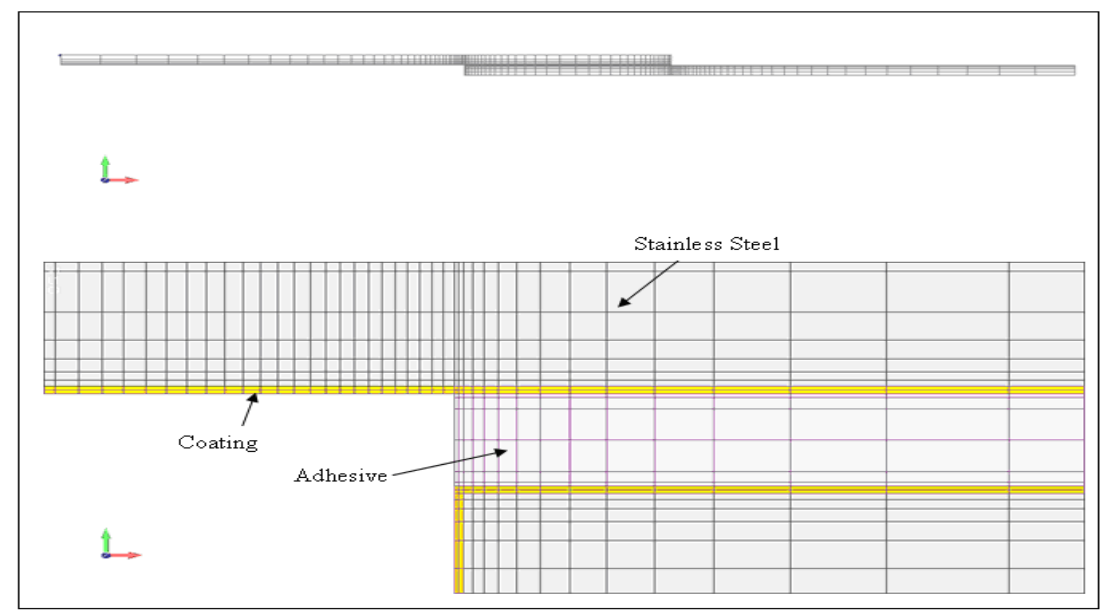

Fig. 9: Single Lap Joint Meshing Details

\section{Material properties}

Typically, steel and adhesive are involved in a steel-to-steel joint. Isotropic elastic and plastic material behavior was assumed for the steel and the adhesive. Similar isotropic elastic material behavior was assumed for the coating. Steel material properties were obtained from public literature. Adhesive material properties were obtained from the client, because they are determined by the bonding process.

Type 316 stainless steel was selected based on the corrosion requirements. Material properties can be obtained from material handbooks, such as the ASM Specialty Handbook. In the analysis, elastic-plastic material properties were input into the finite element model. The adhesive selected for the joint is Loctite Epoxy Weld Bonding Compound 3M 2216. Tensile tests of adhesive were conducted from cast specimens, configured as ASTM D 1002-01 Standard Test Method for Apparent Shear Strength of Single-Lap-Joint Adhesively Bonded Metal Specimens by Tension Loading (Metal-toMetal). Table 2 shows the material property used in the simulation for AISI SS 316L.

Table 2: Material Properties for AISI SS 316L

\begin{tabular}{ll}
\hline Name: & AISI SS 316L \\
\hline Model type: & Linear Elastic Isotropic \\
Default failure criterion: & Unknown \\
Yield strength: & $1.7 \mathrm{e}+008 \mathrm{~N} / \mathrm{m}^{\wedge} 2$ \\
Tensile strength: & $4.8 \mathrm{e}+008 \mathrm{~N} / \mathrm{m}^{\wedge} 2$ \\
Elastic modulus: & $1.9 \mathrm{e}+011 \mathrm{~N} / \mathrm{m}^{\wedge} 2$ \\
Poisson's ratio: & 0.27 \\
Mass density: & $8000 \mathrm{~kg} / \mathrm{m}^{\wedge} 3$ \\
Thermal expansion coefficient: & $1.6 \mathrm{e}-005 /$ Kelvin \\
\hline
\end{tabular}

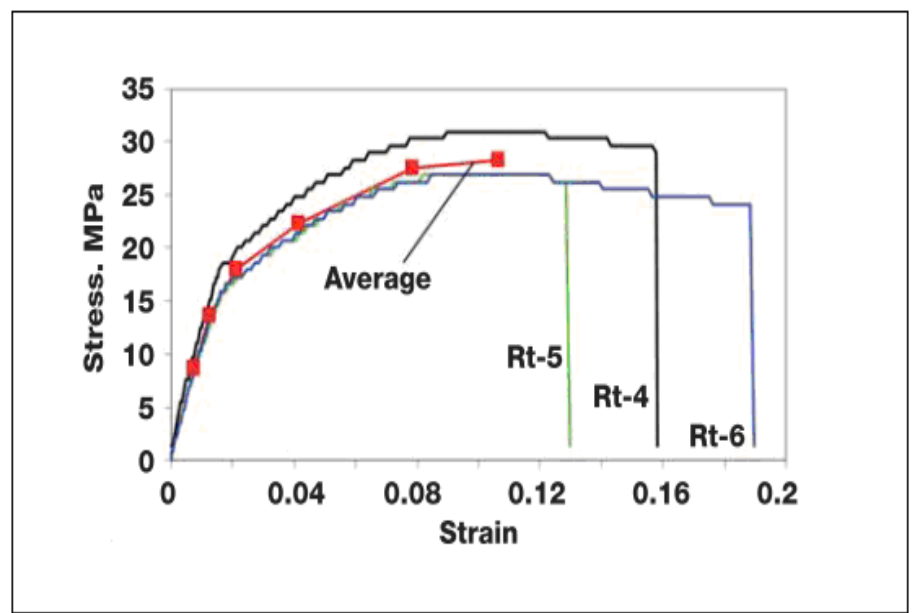

Fig. 10: Stress Strain Curve of 3M 2216 Epoxy Adhesive [14] 
The stress strain curve of the adhesive was used as an input for the material property of adhesive. As observed from the curve, the material yield is observed at $17.5 \mathrm{MPa}$ and the material failure is observed at $25 \mathrm{MPa}$. The chromium and titanium coating has been provided with linear elastic property in accordance with Young's modulus of 27,900 MPa and $25,100 \mathrm{MPa}$, respectively.

\section{Results and discussion}

FEA was performed on a single lap joint bonded with epoxy-based adhesive to find the maximum joint strength for tensile and shear loading. The analyses were carried out with titanium and chromium coated specimens with adhesive thicknesses of $0.125 \mathrm{~mm}$ and $0.25 \mathrm{~mm}$ for the first week of salt spray exposure. Following this, critical tensile loads were obtained from the FEA as shown in Table 3.

In adhesive joints, the applied load on the adherends is transferred on to the adhesive layer mainly by stresses. The results from the analysis of the models were interpreted according to von Mises yield criterion as. The von Mises criterion is applied to calculate whether the stress combination at a given point will cause failure or not [15].

Table 3: Ultimate Load at Different Coating and Adhesive Thickness

\begin{tabular}{lll}
\hline S1 No & Test Case & Ultimate Load (N) \\
\hline 1 & Chromium coated stainless steel with $0.125 \mathrm{~mm}$ thick adhesive & 3572 \\
2 & Titanium coated stainless steel with $0.125 \mathrm{~mm}$ thick adhesive & 2925 \\
3 & Chromium coated stainless steel with $0.25 \mathrm{~mm}$ thick adhesive & 2583 \\
4 & Titanium coated stainless steel with $0.25 \mathrm{~mm}$ thick adhesive & 2005 \\
\hline
\end{tabular}

It is seen from the tensile stress, shear stress and von Mises stress plotted, that the bond strength reduces with the type of coating and that titanium coated stainless steel has lower bond strength when compared with chromium coated stainless steel. However, the variation of these stresses along the bondline has more or less the same pattern, irrespective of coating material.

With respect to adhesive thickness, the bond strength is observed to have reduced at the adhesive thickness of $0.25 \mathrm{~mm}$ from $0.125 \mathrm{~mm}$. The stress variation along the bondline for both chromium and titanium coatings with varying adhesive thicknesses are shown in Figs. 11 to 16. These results are plotted for the ultimate loads of the respective load cases. Increasing the adhesive thickness resulted in a marked decrease in the maximum tensile and maximum shear stresses and von Mises stresses at the ends of the overlap. This reduction stress magnitude is accompanied by a reduction in adhesive plastic deformation. It is seen that by increasing the adhesive thickness of $0.125 \mathrm{~mm}$ to $0.25 \mathrm{~mm}$, the equivalent maximum stress is reduced by $6.3 \%$.

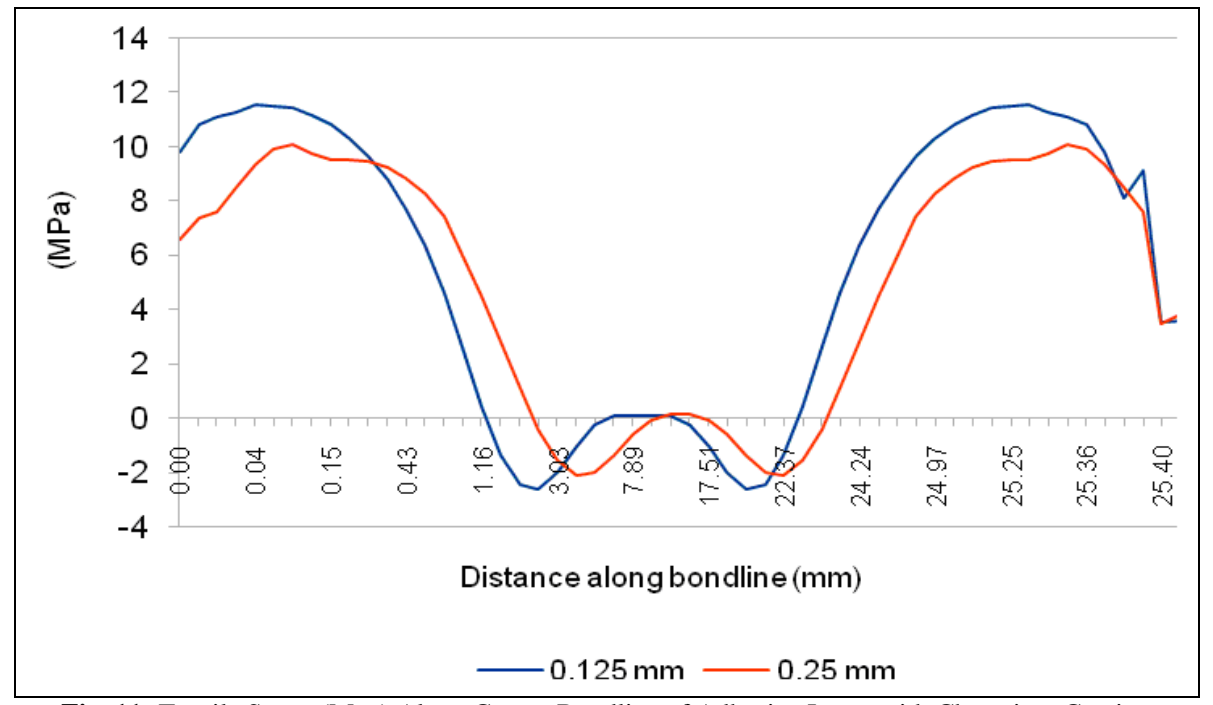

Fig. 11: Tensile Stress (Mpa) Along Corner Bondline of Adhesive Layer with Chromium Coating 


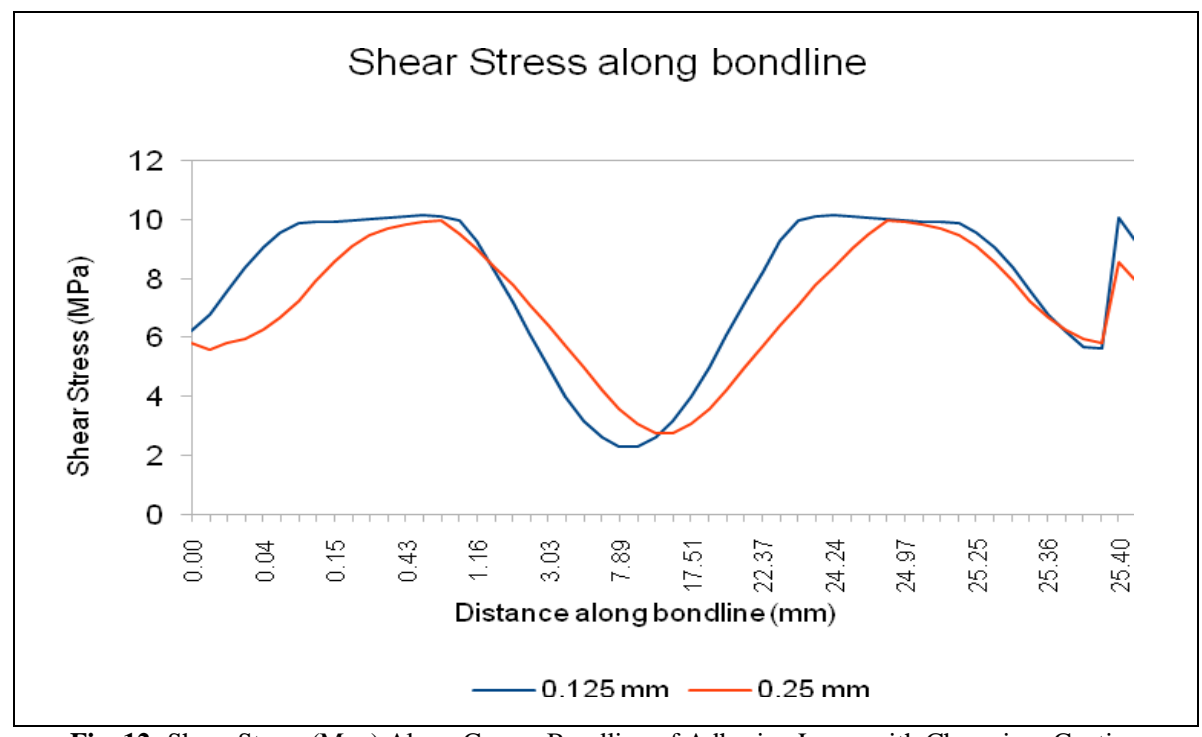

Fig. 12: Shear Stress (Mpa) Along Corner Bondline of Adhesive Layer with Chromium Coating

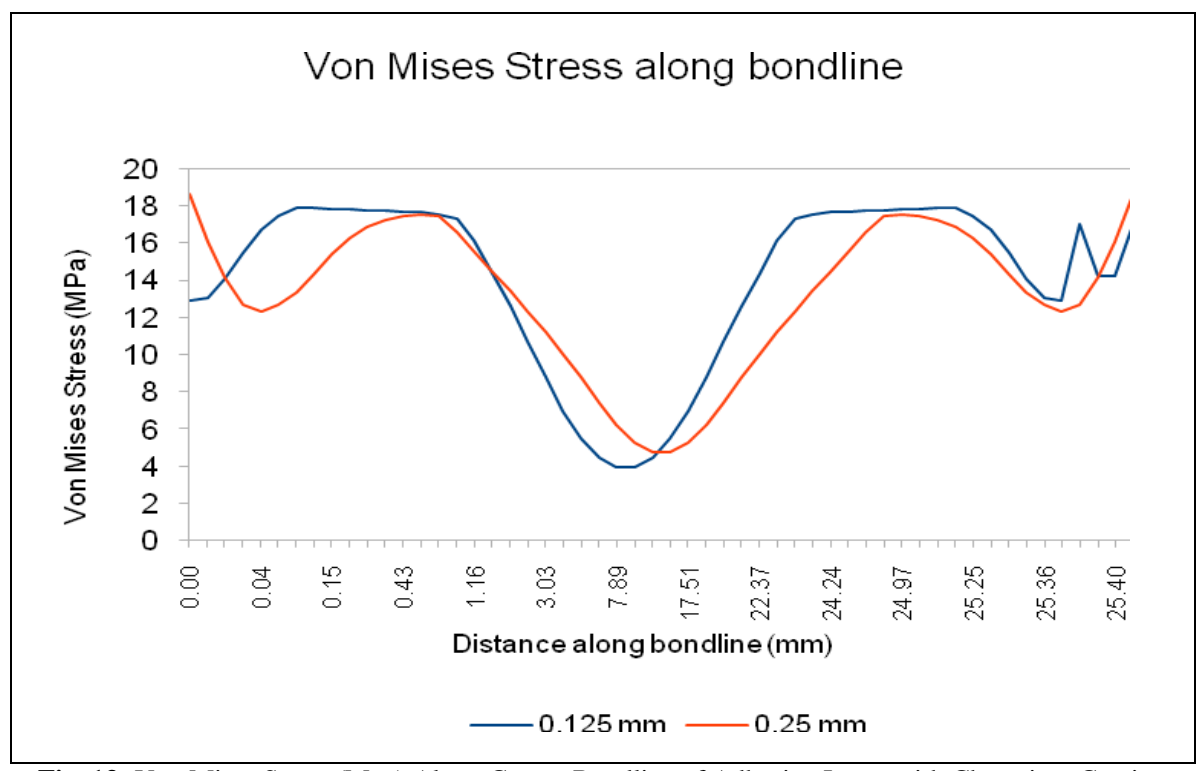

Fig. 13: Von Mises Stress (Mpa) Along Corner Bondline of Adhesive Layer with Chromium Coating

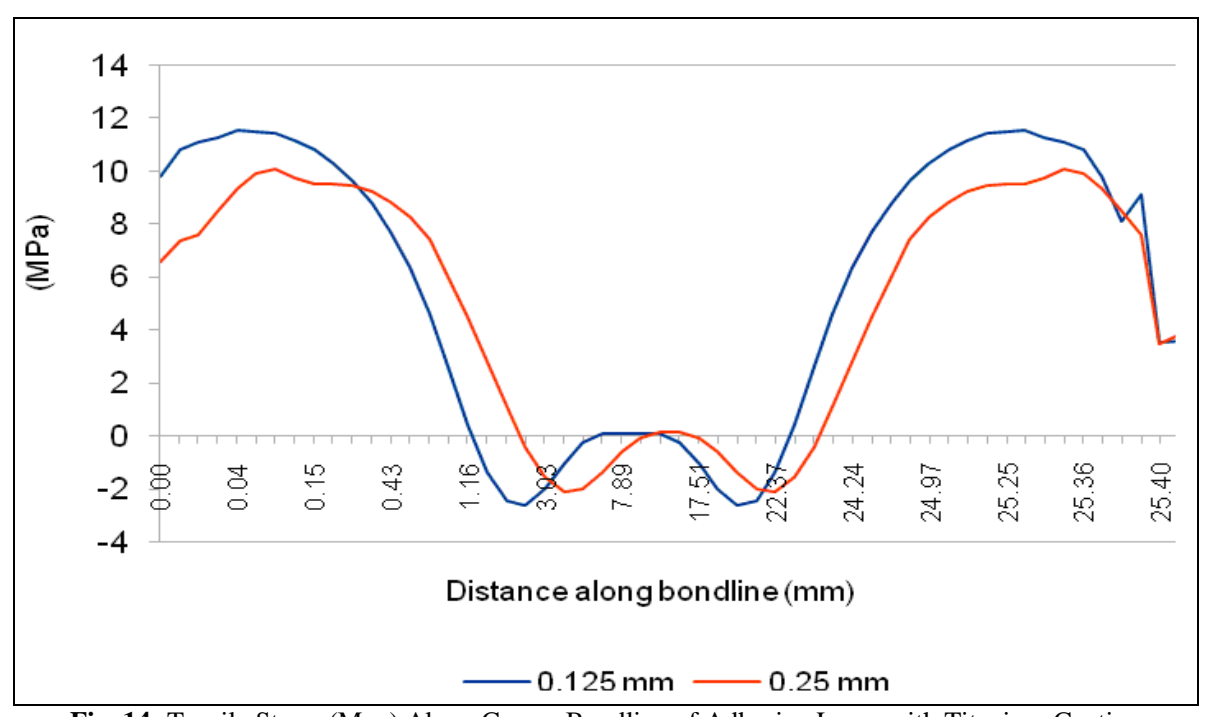

Fig. 14: Tensile Stress (Mpa) Along Corner Bondline of Adhesive Layer with Titanium Coating 


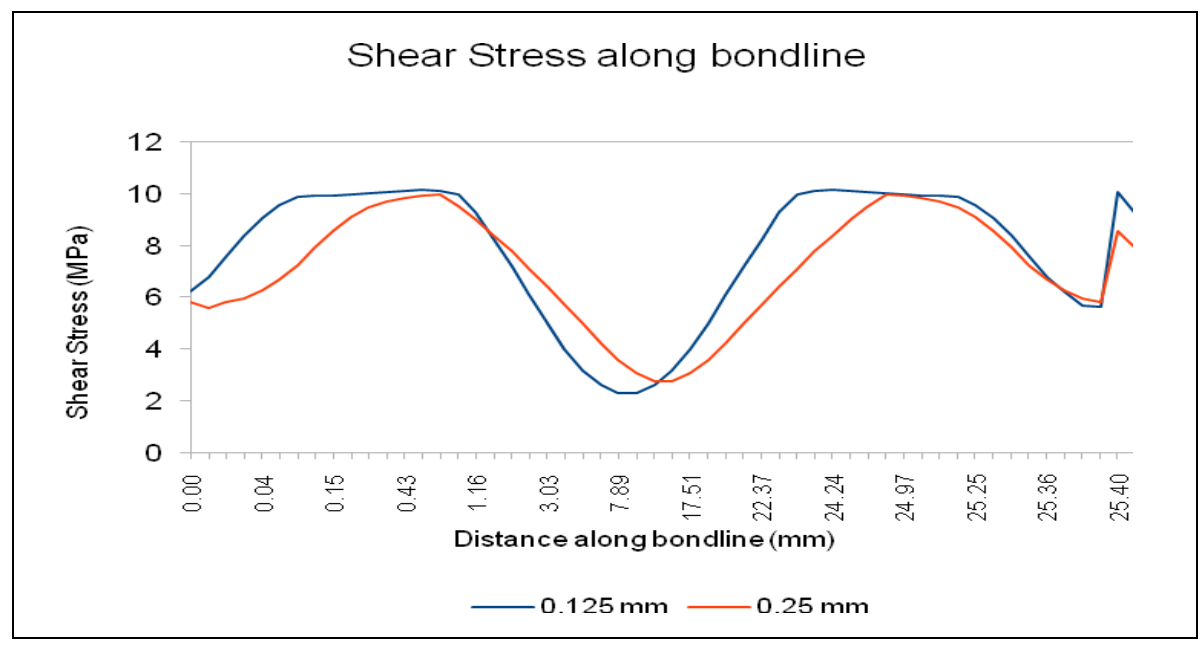

Fig. 15: Shear Stress (Mpa) Along Corner Bondline of Adhesive Layer with Titanium Coating

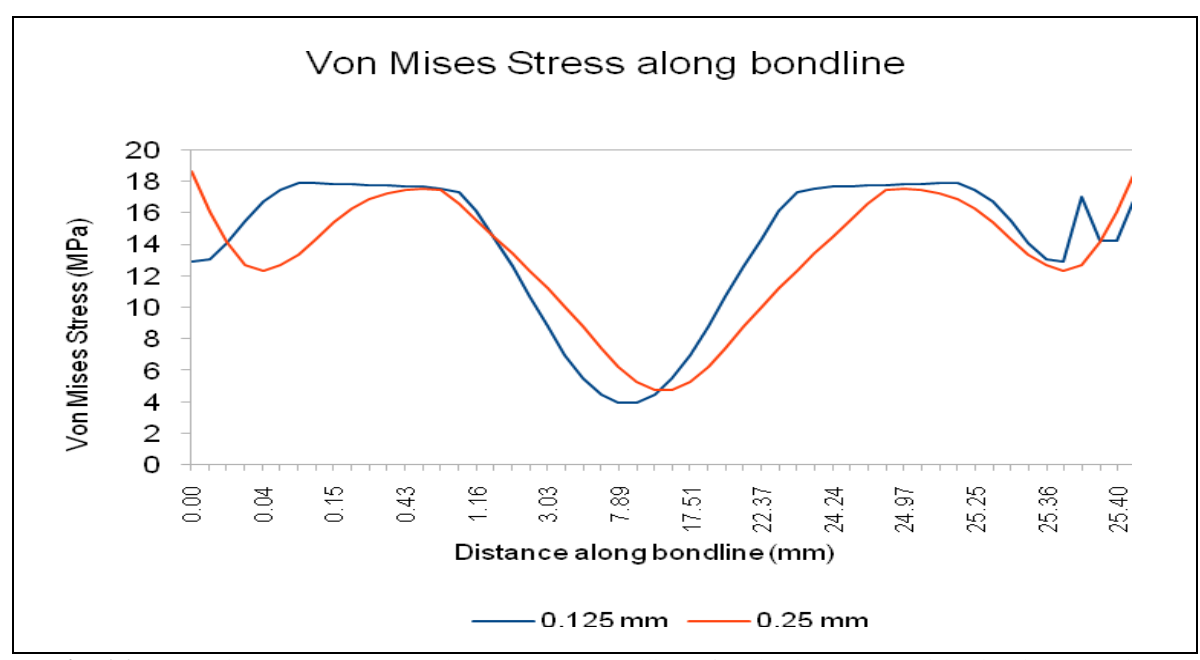

Fig. 16: Von Mises Stress (Mpa) Along Corner Bondline of Adhesive Layer with Titanium Coating

\section{Visual examination}

Post tensile failure examination of the adhesively bonded sample was conducted. Fig. 17 shows a $\mathrm{Cr}_{2} \mathrm{O}_{3}$ treated sample after failure. Evidence of corrosion was observed around the edges. This was assumed to be crevice corrosion because of the location of corrosion products from exposed edges where crevice conditions would be expected to be formed during marine exposure. It is suggested that the decrease in bond strength for the $\mathrm{Cr}_{2} \mathrm{O}_{3}$ treatment during marine exposure was due to crevice corrosion. However, failed samples with $\mathrm{TiO}_{2}$ treatment did not show the same degree of crevice corrosion.

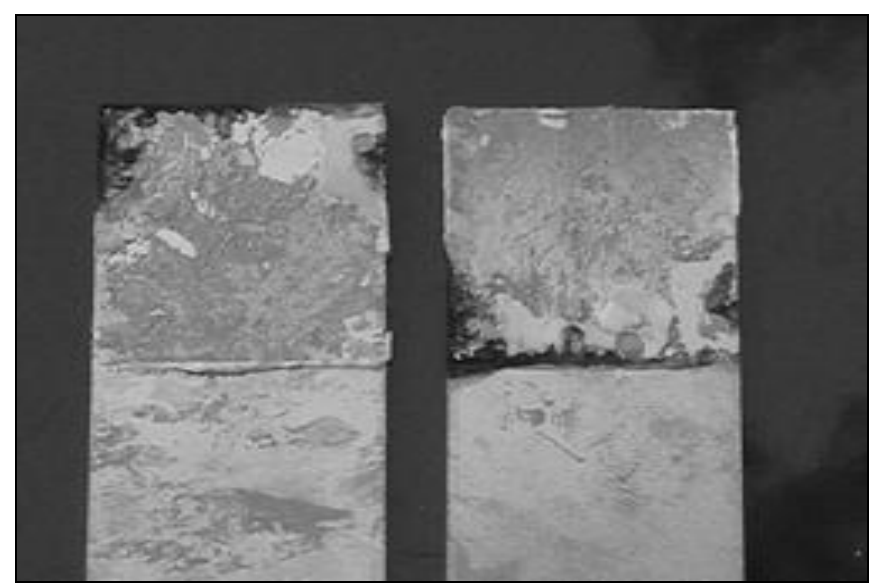

Fig. 17: Adhesive and Cohesive Due to Crevice Corrosion of SS 316L 


\section{Conclusion}

1) Cyclic polarization tests indicated that a titanate based chemical surface treatment improved corrosion resistance for SS 316L compared to $\mathrm{Cr}_{2} \mathrm{O}_{3}$ surface treatment.

2) Salt spray testing appearance decline in bonding strength for Chromium and Titanium

3) Residual strength of SS 316L, chemically treated with $\mathrm{TiO}_{2}$ and adhesively bonded to itself, increased significantly compared to chemical treatment with $\mathrm{Cr}_{2} \mathrm{O}_{3}$ after they are exposed to a corrosion environment for a sustained period of time.

4) Increasing the adhesive thickness resulted in a marked decrease in the maximum tensile and maximum shear stresses and von Mises stresses at the ends of the overlap

\section{Acknowledgements}

The authors would like to express their gratitude to Professor Richard Brown for his continuous enthusiasm, inspiration, and mentoring. My great appreciation also goes to all the technical and library staff at Rhode Island University for their assistance during this project. The authors are also grateful for the financial support of public authority of applied education and training

\section{References}

[1] Occupational Safety and Health Standards, USA. Chromium $\quad$ (VI); $29 \quad$ CFR Part 1910.1026. http://www.osha.gov/pls/oshaweb/owadisp.show_document?p_table=STANDARDS\&p_id=13096. Accessed 21-06-2009

[2] M. Braic, S. Zamfira, M. Balaceanu, V. Braic, G. Pavelescu, A. Zamfira, Corrosion Resistance Of TiN Coated 316L Stainless Steel In Artificial Physiological Solution, Journal of Optoelectronics and Advanced Materials 5(2) (2003) 503-510.

[3] S. Wang, R.C. Newman, Crevice Corrosion of Type 316L Stainless Steel in Alkaline Chloride Solutions, NACE International 60(5) (2004).

[4] T. Singh, H. Singh, H. Singh, Characterization, Corrosion Resistance, and Cell Response of High-Velocity Flame-Sprayed HA and HA/TiO Coatings on 316L SS, Journal of Thermal Spray Technology 21(5) (2012) 917-927. http://dx.doi.org/10.1007/s11666-012-9782-x.

[5] F. Benoit-Marquie, E. Puech-Costes, A.M. Braun, E. Oliveros, M.-T. Maurette, Photocatalytic degradation of 2, 4-dihydroxybenzoic acid in water: efficiency optimization and mechanistic investigations, Journal of Photochemistry and Photobiology 108 (1997) 65-71. http://dx.doi.org/10.1016/S1010-6030 (96)04501-7.

[6] S. El Hajjaji, A. Guenbour, A. Ben Bachir, L. Aries, Effect of treatment baths nature on the Characteristics of conversion coatings modified by electrolytic alumina deposits, Corrosion Science 42 (2000) 941-956. http://dx.doi.org/10.1016/S0010-938X (99)00124-9.

[7] S. El Hajjaji, A. Ben Bachir, L. Aries, An evaluation of the corrosion resistance and adhesion properties of an epoxy-nanocomposite on a hotdip galvanized steel (HDG) treated by different kinds of conversion coatings, Surface and Coatings Technology 205 (2011) $4649-4657$. http://dx.doi.org/10.1016/j.surfcoat.2011.04.001.

[8] F. Senocq, S. El Hajjaji, J. Roy, L. Aries, Preparation and characterization of electrolytic alumina deposit on austenitic stainless steel, Science and Technology of Advanced Materials 6 (2006) 519-524.

[9] L. Bamoulid, F. Benoit-Marquié, L. Aries et al., An efficient protection of stainless steel against corrosion: Combination of a conversion layer and titanium dioxide deposit, Surface and Coatings Technology 201 (2006) 2795.

[10] K. Ikegami, "Strength Estimation of Adhesively Bonded Joint by using the Adhesive Strength Law" Proceedings of the 5th International Congress of Croatian Society of Mechanics (CD-Rom), Croatia, June 2006; pp. 545-549.

[11] F. Matejicek, P. Raos, M. Lucic, "Numerical Analysis of Single-Lap Adhesive Joint" Proceedings of the 4th International Congress of Croatian Society of Mechanics (CD-Room), Bizovac, 2003.

[12] M. Lucic, A. Stoic, J. Kopac, "Experimental and Numerical Analysis of Lap Length Influence on Strength of Adhesively Bonded Joint" Proceedings of PPS-18(CD-Book), Guimaraes, Portugal, 2002.

[13] P. Raos, M. Lucic, F. Matejicek, Investigation of aluminum single lap adhesively bonded joints, Achievements in Materials and Manufacturing Engineering 15 (2006) 12.

[14] Y-P. Yang, G.W. Ritter, D.R. Speth, Finite Element Analyses of Composite-to-Steel Adhesive Joints, Advanced Materials \& Processes 169 (2011) 24.

[15] M. Zgoula, A.D. Crocombeb, Numerical modeling of lap joints bonded with a rate-dependent adhesive, International Journal of Adhesion \& Adhesives 24(4) (2004) 355-366. http://dx.doi.org/10.1016/j.ijadhadh.2003.11.006. 